\title{
Influence of age and sex on winter site fidelity of sanderlings Calidris alba
}

Pedro M Lourenço ${ }^{\text {corresp.. }}{ }^{1}$, José A Alves ${ }^{2,3}$, Jeroen Reneerkens ${ }^{4}$ ，A H Jelle Loonstra ${ }^{4}$, Peter M Potts ${ }^{5}$, José P Granadeiro $^{1}$, Teresa Catry ${ }^{1}$

${ }^{1}$ Centro de Estudos do Ambiente e do Mar (CESAM), Departamento de Biologia Animal, Faculdade de Ciências, Universidade de Lisboa, Lisboa, Portugal

2 Centro de Estudos do Ambiente e do Mar (CESAM), Universidade de Aveiro, Aveiro, Portugal

3 South Iceland Research Centre, University of Iceland, Selfoss, Iceland

4 Conservation Ecology Group, Groningen Institute for Evolutionary Life Sciences (GELIFES), University of Groningen, Groningen, The Netherlands

5 Farlington Ringing Group, Southampton, Hampshire, United Kingdom

Corresponding Author: Pedro M Lourenço

Email address: p.m.g.lourenco@gmail.com

Many migratory bird species show high levels of site fidelity to their wintering sites, which confers advantages due to prior knowledge, but may also limit the ability of individual to move away from degrading sites or to detect alternative foraging opportunities. Winter site fidelity often varies among age groups, but sexual differences have seldom been recorded in birds.

We studied a population of individually colour-marked sanderlings wintering in and around the Tejo estuary, a large estuarine wetland on the western coast of Portugal. For 160 individuals, sighted a total of 1249 times between November 2009 and March 2013, we calculated the probability that they moved among five distinct wintering sites and how this probability is affected by distance between them. To compare site fidelity among age classes and sexes, as well as within the same winter and over multiple winters, we used a Site Fidelity Index (SFI). Birds were sexed using a discriminant function based on biometrics of a large set of molecularly sexed sanderlings $(n=990)$ with data from. The vast majority of birds were observed at one site only, and the probability of the few detected movements between sites was negatively correlated with the distance among each pair of sites. Hardly any movements were recorded over more than $15 \mathrm{~km}$, suggesting small home ranges. SFI values indicated that juveniles were less site-faithful than adults which may reflect the accumulated knowledge and/or dominance of older animals. Among adults, females were significantly less site faithful than males. A sexual difference in winter site fidelity is unusual in shorebirds. SFI values show site-faithfulness is lower when multiple winters were considered, and most birds seem to chose a wintering site early in the season and use that site throughout the winter. Sanderlings show a very limited tendency to explore alternative wintering options, which might have implications 
for their survival when facing habitat change or loss (e.g. like severe beach erosion as can be the case at one of the study sites). 
1 Manuscript for PeerJ (dd. 12 August 2016)

2

3

4 Influence of age and sex on winter site fidelity of sanderlings

5

6 Pedro M. Lourenço ${ }^{1}$, José A. Alves ${ }^{2,3}$, Jeroen Reneerkens ${ }^{4}$, A.H. Jelle Loonstra ${ }^{4}$, Pete M. Potts ${ }^{5}$, 7 José P. Granadeiro ${ }^{1} \&$ Teresa Catry $^{1}$

9 'Centro de Estudos do Ambiente e do Mar (CESAM), Departamento de Biologia Animal,

10 Faculdade de Ciências da Universidade de Lisboa, 1749-016 Lisboa, Portugal

$11{ }^{2}$ Centro de Estudos do Ambiente e do Mar (CESAM), Universidade de Aveiro, Campus

12 Universitário de Santiago, 3180-193, Aveiro, Portugal

$13{ }^{3}$ South Iceland Research Centre, University of Iceland, Tryggvagata 36, IS-800 Selfoss, Iceland

$14{ }^{4}$ Conservation Ecology Group, Groningen Institute for Evolutionary Life Sciences (GELIFES),

15 University of Groningen, P.O. Box 11103, 9700 CC Groningen, The Netherlands

16 5Peter M Potts (Farlington Ringing Group) c/o Solent Court Cottage, Chilling Lane, Warsash,

17 Southampton, Hampshire, SO31 9HF, England, UK

22 Corresponding author:

23 P.M. Lourenço, email: p.m.g.lourenco@gmail.com, tel: (+351) 938468585 


\section{Abstract}

27 Many migratory bird species show high levels of site fidelity to their wintering sites, which

28 confers advantages due to prior knowledge, but may also limit the ability of individuals to move away from degrading sites or to detect alternative foraging opportunities. Winter site fidelity often varies among age groups, but sexual differences have seldom been recorded in birds.

31 We studied a population of individually colour-marked sanderlings wintering in and around the Tejo estuary, a large estuarine wetland on the western coast of Portugal. For 160 individuals, sighted a total of 1249 times between November 2009 and March 2013, we calculated the probability that they moved among five distinct wintering sites and how this probability is affected by distance between them. To compare site fidelity among age classes and sexes, as well as within the same winter and over multiple winters, we used a Site Fidelity Index (SFI). Birds were sexed using a discriminant function based on biometrics of a large set of molecularly sexed sanderlings $(n=990)$ with data from. The vast majority of birds were observed at one site only, and the probability of the few detected movements between sites was negatively correlated with the distance among each pair of sites. Hardly any movements were recorded over more than 15

$41 \mathrm{~km}$, suggesting small home ranges. SFI values indicated that juveniles were less site-faithful than 42 adults which may reflect the accumulated knowledge and/or dominance of older animals. Among adults, females were significantly less site faithful than males. A sexual difference in winter site

44 fidelity is unusual in shorebirds. SFI values show site-faithfulness is lower when multiple winters 45 were considered, and most birds seem to chose a wintering site early in the season and use that 46 site throughout the winter. Sanderlings show a very limited tendency to explore alternative 47 wintering options, which might have implications for their survival when facing habitat change 
48 or loss (e.g. like severe beach erosion as can be the case at one of the study sites). 


\section{Introduction}

Although migratory birds are extremely mobile, they are often remarkably site-faithful to their breeding (e.g. Harvey et al. 1979; Jackson 1994), wintering (e.g. Burton \& Evans 1997; Catry et al. 2003; Leyrer et al. 2006) and staging sites (Gudmundsson \& Lindström 1992; Kruckenberg \& Borbach-Jaene 2004, Loonstra et al. 2016), both within the same season and among years. Such high levels of site fidelity are likely to confer advantages related to prior ownership of territories, previous knowledge of foraging locations, potential nest sites and local predators, and maintenance of social position within local dominance structures (Greenwood \& Harvey 1982; Alerstam 1990; Snell-Rood \& Cristol 2005).

However, when confronted with a rapidly changing environment, the regular use of the same set of sites over the years may expose individuals to increasingly poorer conditions and habitats (Battin 2004), when a traditionally used site suffers negative changes over time (e.g. Porzig et al. 2014) e.g. through a limitation in the use of all available habitat (Matthiopoulos et al. 2005). Therefore, the ability of animals to disperse and/or sample new areas can be of critical importance for highly site faithful species, under the current fast pace of global environmental change. Unfortunately, evaluating the use of multiple sites over large areas by the same individuals requires intensive effort to repeatedly detect marked individuals, which hinders the possibility of expanding efforts over large areas and impedes the detection of dispersion over longer distances. In addition, the traditionally low rate of movement among sites hinders the use of remote tracking techniques as the very large sample sizes needed to detect rare movements would greatly increase the cost of such an endeavour (e.g. Nathan et al. 2003; Hobson 2005). 
72 and/or exploratory behaviours during which they search for places to ultimately settle (Clobert et

73 al. 2001). However, few studies have focused on age effects in winter site fidelity in migratory

74 birds, and the available studies have reported conflicting results in this issue. Juvenile western

75 sandpipers Calidris mauri showed larger home ranges and weaker homing behaviour than adults

76 in winter (Warnock \& Takekawa 1996; Baccetti et al. 1999), and younger white-fronted geese

77 Anser albifrons were more likely to move among wintering sites than older birds (Wilson et al.

78 1991). However, there were no differences in winter site fidelity among different age groups of

79 either pink-footed geese Anser brachyrhynchus (Fox et al. 1994) or American black ducks Anas

80 rubripes (Diefenbach et al. 1988).

81 Sex can also influence site fidelity. Most research on site fidelity in migratory birds has

82 focused on the breeding season, generally showing that males tend to be more site-faithful and

83 disperse over shorter distances between years than females (Clarke et al. 1997, Gunnarsson et al.

84 2012). Such a pattern has been explained by the increased fitness benefits of prior knowledge of

85 the local environment for the sex that establishes territories (Greenwood 1980; Gienapp \&

86 Merilä 2011). This stronger territoriality and site fidelity in males observed in a reproductive

87 context could lead to a similar tendency in the wintering areas, resulting in a higher

88 predisposition for site-fidelity even in a gregarious (wintering) context. On the other hand, sexual

89 dimorphism or behavioural differences between sexes may imply different ecological

90 requirements during winter, such as differences in diet (e.g. Alves et al. 2013) or roost selection

91 (e.g. Donázar \& Feijóo 2002). These differences could also drive sexual differences in site

92 fidelity if required resources are heterogeneous in space. However, sexual differences in winter

93 site fidelity have seldom been recorded in birds, being mostly restricted to species that frequently

94 move during winter following spatial variation in food resources or that have family group 
95 composition affect their winter distribution (e.g. Roberts \& Cook 1999; Wunderle et al. 2014).

96 Studies in highly site-faithful long distance migrants, such as waders, have not shown sexual

97 differences thus far (e.g. Warnock \& Takekawa 1996; Catry et al. 2012).

98 Over the years, waders have been the focus of many individual-based studies, providing a

99 significant source of information regarding site fidelity and individual movements. When faced

100 with short-term changes in habitat quality/availability, some waders seem to be able to respond

101 by moving up to over $100 \mathrm{~km}$ to more favourable areas (e.g. Kirby \& Lack 1993; Takekawa et

102 al. 2002; van Gils et al 2006, Lourenço et al. 2010), while others continue to use

103 degraded/changed habitats (Connolly \& Colwell 2005; Taft et al. 2008) apparently due to limited

104 ability to increase or change home ranges (Taft et al. 2008). Understanding the level of site

105 fidelity exhibited by individuals at a small spatial-scale (e.g. among sites within a single wetland)

106 when compared with the continent-wide scale of their migration to and from their high-Arctic

107 breeding sites (Loonstra et al. 2016) and, by opposition, the predisposition to disperse over

108 increasing distances under stable conditions may provide some insights into the general ability of

109 wader species to explore potential new areas or respond to short-term changes in their

110 environment.

111 Sanderlings are common and widespread waders in coastal areas worldwide (Grond et al.

112 2015; Conklin et al. 2016). They are mainly associated with coarse sediment habitats, such as

113 sandy beaches and sand or muddy-sand flats, which are particularly prone to quick changes

114 through sediment migration and coastal erosion (Pethick 2001) and often affected by human

115 disturbance (e.g. Burger 1991; Thomas et al. 2003). Sanderlings have been described as very site

116 faithful and seem to have small home ranges at both wintering and staging areas (review in

117 Reneerkens et al. 2009). In this study we use a dataset of observations of colour-marked 
118 sanderlings wintering in and around a large estuarine wetland to compare the level of winter site

119 fidelity, within a single winter and among multiple winters, between sexes and age groups, and

120 estimating the probability of these birds naturally dispersing over increasing distances under

121 relatively stable conditions.

122

123

124 Methods

125

126 Study area

127 Field work was carried out in the Tagus estuary, Portugal, one of the largest tidal wetlands in

128 Western Europe, and comprised five sites known to harbour sanderlings during winter. Three of

129 the sites are located within the estuarine area (Alcochete, Samouco and Seixal), and two are

130 located on the oceanic coast near the mouth of the Tejo river (Caparica and Oeiras; Fig 1). The

131 minimum distance between a pair of sites is $3.1 \mathrm{~km}$ (Alcochete and Samouco), and the maximum

132 is $29.8 \mathrm{~km}$ (Alcochete and Oeiras; Figs. 1). All study sites include foraging and roosting areas,

133 the former located in the intertidal flats and the later situated above the high water mark. In

134 Alcochete birds also roost on a saltpan located near the beach, which was also routinely

135 monitored during the study. All sites harbour sanderling flocks throughout the winter with

136 average counts of 75-126 individuals per site (more details regarding the study area in Lourenço

137 et al. 2015).

138

139 Study population and data analysis

140 A total of 374 sanderlings were captured and ringed with individual colour-ring combinations 
141 in all three sites within the Tejo estuary in five consecutive non-breeding seasons between

142 2008/9 and 2012/13. Some birds were caught during late August and thus could still have been

143 passage migrants, but since the re-sighting data refers only to the wintering period, this will not

144 affect our winter site fidelity analysis. At capture, all birds were aged based on plumage

145 characteristics, being classified as either first winter (hereafter referred as juveniles) or adults.

146 Biometric data (wing length and tarsus length measured to the nearest $\mathrm{mm}$; bill length and total

147 head length measured to the nearest $0.1 \mathrm{~mm}$ ) were also collected for most individuals to

148 determine their sex. Sex of measured birds was determined based on a function derived from a

149 generalised linear model (GLM) of biometric data from 990 molecularly sexed sanderlings

150 captured in Mauritania and Ghana in a concurrent study (see appendix for details). Since juvenile

151 sandpipers can have shorter wing lengths than adults (Yosef \& Meissner 2006), which is also

152 true for sanderlings captured in the Tejo estuary (juveniles: $125.0 \pm 0.3 \mathrm{~mm}, \mathrm{n}=89$; adults:

$\left.153127.1 \pm 0.2 \mathrm{~mm}, \mathrm{n}=212 ; \mathrm{t}_{299}=5.03, \mathrm{p}<0.001\right)$, we only sexed adult birds through this method as

154 wing is a key biometric sexing parameter (see appendix). The GLM correctly assigned the sex of

155 a large proportion of the 990 birds used to derive the model ( $84 \%$; see appendix), but to

156 minimize the risk of incorrect assignments all birds with a sex assignment probability below $75 \%$

157 (i.e. $\left.0.25 \leq P_{(\text {male })} \leq 0.75 ; \mathrm{n}=24\right)$ were excluded from the sex-related fidelity analysis. This

158 resulted in 102 sexed birds, 64 males and 38 females.

159 From 2009/10 to 2012/13, during the sanderling wintering period (November-March), the

160 study sites were visited frequently by us and many volunteer observers and the presence and

161 identity of colour-marked birds was recorded. A total of 317 marked individuals were sighted,

162 including 302 birds ringed locally and another 15 marked elsewhere (Greenland, Iceland and The

163 Netherlands). The full dataset included 2358 sightings. Since the dataset includes many sightings 
164 obtained during haphazard visits of volunteers ( $21 \%$ of all individual sightings used in the

165 analysis), we do not know whether the searching effort was similar for all sites, because

166 volunteer observers will not have contacted us when they did not find a colour-ringed sanderling

167 during their visits. We also suspect that the sites outside the estuary are likely to have been

168 visited less often than the sites located within the estuary. For the same reason, sightings are not

169 evenly spread over each winter and over different winters (Table 1).

170 In order to minimize the risk of having incorrect readings affecting our analyses, we limited

171 our analysis to include birds that had been sighted a minimum of three times in a given area/year

172 which resulted in 160 individuals (36 juveniles and 124 adults) for which we had a total of 1249

173 sightings (Table 1). For 101 of these individuals we had data over multiple years (65 seen in 2

174 winters, 28 seen in three winters and 8 seen in 4 winters). For each study site we calculated the

175 proportion of individuals that were recorded only locally, and the proportion also recorded in

176 other sites, both within a single winter (using the average of all four winters) and over multiple

177 winters. To evaluate how the probability of dispersal varies with distance we used Generalized

178 Linear Mixed-effects Models (GLMM) with logit link functions to relate a binomial variable

179 indicating whether an individual sighted at a given site was later seen at each of the other sites,

180 or only seen at the first site (movement distance $=0 \mathrm{~km}$ ), to the distance among each pair of

181 sites. Individual was used as a random factor in the GLMMs. This analysis was performed to

182 assess inter-annual site fidelity (i.e. data from multiple winters), using all available sightings of

183 each individual, and also intra-annual site fidelity in which case we used data available for each

184 individual each year and used year as covariate. Age and sex were not included in this analysis

185 because no juvenile birds were sexed (see above). The GLMM analysis were performed using

186 package lme4 v1.1-11 in R (R Core Team 2014). 
187 In order to test differences in site fidelity between sexes and age classes, as well as differences

188 in the site fidelity within a single winter and over multiple winters we calculated a site fidelity

189 index (SFI) described by Catry et al. (2012). This index takes into account the number of sites

190 used, the number of observed changes between sites and the total number of sightings for each

191 individual:

192

$$
S F I=1-\left[\left(\frac{n_{i}-1}{n-1}\right) \times\left(\frac{p_{i}}{o_{i}-1}\right)\right]
$$

where $n_{i}$ is the number of sites used by individual $i, n$ is the total number of sites surveyed, $p_{i}$ is the observed number of changes between sites performed by individual $i$ and $o_{i}$ is the total number of sightings of individual $i$. SFI ranges from zero (no site fidelity) to one (complete site fidelity). For each individual, SFI values were calculated within each winter (intra-annual SFI) and for all winters combined (inter-annual SFI).

To investigate sex differences in site fidelity, we compared both intra-annual and inter-annual SFI values for males and females. For birds with data for multiple winters we used the average intra-annual SFI, and in both cases we used Mann-Whitney tests to compare SFI scores. Two approaches were used to compare site fidelity among age classes. One compared the intra-annual SFI values for juvenile and adult birds for the winter when each individual was ringed/aged, through a Mann-Whitney test; the other used only birds ringed as juveniles and sighted over multiple winters, in which case we made a pair-wise comparison of intra-annual SFI values calculated for each juvenile in their first winter and in the subsequent winter (when adult) with the most sightings of that particular individual, using a Wilcoxon matched pairs test.

209 Finally, in order to compare site fidelity within the same winter and over multiple winters, we 
210 made a pair-wise comparison of intra and inter-annual SFI values for all adult birds sighted over

211 multiple years using a Wilcoxon matched pairs test. There could be some biases when comparing

212 inter-annual SFI of individuals with different numbers of sightings in each winter, but this

213 problem would only affect comparisons among individuals and not pair-wise comparisons for

214 each individual. Note that birds ringed as juveniles were excluded from this analysis because the

215 tests described above showed that sanderlings are less site faithful in their first winter (see

216 below). Data are presented as average $\pm \mathrm{SE}$.

\section{Results}

220 The majority of individuals $(93.6 \pm 0.7 \%, n=4$ winters with an average $73 \pm 25$

221 individuals/winter) were always sighted at the same site within a given winter (Fig. 1). The same

222 pattern was observed for multiple winters (Fig. 1) but the proportion of birds that were only

223 observed at a single site decreased with the number of winters considered, with $81.5 \%(n=65)$ for

2242 winters, $67.9 \%(n=28)$ for 3 winters and $62.5 \%(n=8)$ for 4 winters. Bird movements were

225 more likely to occur between sites in close proximity, namely between Alcochete and Samouco,

226 between Samouco and Seixal and between Seixal and Caparica (Fig. 1).

227 In fact, the GLMMs indicated that the probability of movement was negatively affected by

228 distance, with lower probabilities of dispersal between sites further away both within one winter

$229(\beta=-0.609 \pm 0.071, \mathrm{z}=8.61, \mathrm{p}<0.001)$ and over multiple winters $(\beta=-0.278 \pm 0.026, \mathrm{z}=10.57$,

$230 \mathrm{p}<0.011$; Fig. 2). In the analysis for a single winter the covariable 'year' had no effect on the

231 probability of movement $(\mathrm{z}=0.45, \mathrm{p}>0.5)$. In fact, there was only a single case of dispersal

232 between sites located at a distance of over $20 \mathrm{~km}$. No marked birds were ever detected at Oeiras 
233 even though the site was frequently used by non-marked sanderlings.

234 Females exhibited significantly lower intra-annual SFI values than males (intra-annual

$235 \mathrm{SFI}_{\text {male }}=0.999 \pm 0.001, \mathrm{n}=64$; intra-annual $\mathrm{SFI}_{\text {female }}=0.991 \pm 0.005, \mathrm{n}=38 ; \mathrm{Z}=2.15, \mathrm{p}<0.05 ;$ Fig. 3A),

236 while there was no significant difference in inter-annual SFI values between sexes (inter-annual

$237 \mathrm{SFI}_{\text {male }}=0.989 \pm 0.004, \mathrm{n}=42$; inter-annual $\mathrm{SFI}_{\text {female }}=0.979 \pm 0.007, \mathrm{n}=31 ; \mathrm{Z}=1.40, \mathrm{p}>0.1$; Fig. 3B).

238 Juvenile birds had significantly lower intra-annual SFI values than adults in the winter when they

239 were ringed/aged (intra-annual $\mathrm{SFI}_{\text {adult }}=0.997 \pm 0.003, \mathrm{n}=126$; intra-annual

$240 \mathrm{SFI}_{\text {juvenile }}=0.975 \pm 0.009, \mathrm{n}=34 ; \mathrm{Z}=3.56, \mathrm{p}<0.001 ;$ Fig. $\left.3 \mathrm{C}\right)$. The intra-annual SFI values of birds

241 ringed as juveniles increased in subsequent winters (intra-annual $\mathrm{SFI}_{\text {first winter }}=0.977 \pm 0.009, \mathrm{n}=24$;

242 intra-annual $\mathrm{SFI}_{\text {subsequent winter }}=0.995 \pm 0.005, \mathrm{n}=24 ; \mathrm{Z}=1.99, \mathrm{p}<0.05$; Fig. 3D). For adult birds,

243 inter-annual SFI values were significantly lower than intra-annual SFI values (intra-annual SFI

$244=0.995 \pm 0.003, \mathrm{n}=101$; inter-annual $\mathrm{SFI}=0.985 \pm 0.004, \mathrm{n}=101 ; \mathrm{Z}=2.59, \mathrm{p}<0.01$; Fig. 3E).

\section{Discussion}

247 Despite some movements among sites, our data show high levels of short-scale winter site

248 fidelity in sanderlings wintering in the Tejo estuary region, especially if we consider that the

249 study sites are located in close proximity, with a minimum distance of just $3.1 \mathrm{~km}$ between sites.

250 Such high level of site fidelity is remarkable for a long-distance migrant accustomed to fly

251 thousands of kilometres (several birds sighted in the Tejo were marked in breeding sites in

252 northern Greenland, roughly $4000 \mathrm{~km}$ away, J. Reneerkens unpub. data), and which disperses

253 over a huge latitudinal range during the winter (in the East Atlantic Flyway at least $58^{\circ} \mathrm{N}$ to $23^{\circ} \mathrm{S}$,

254 e.g. Loonstra et al. 2016), but it is in line with previous studies both on sanderlings (Evans et al.

255 1980; Myers et al. 1990; Gudmundsson \& Lindström 1992) and other waders (e.g. Burton \& 
256 Evans 1997; Leyrer et al. 2006; Catry et al. 2012).

257 However, sanderlings do visit other sites and, after four winters, roughly one third of all birds

258 had already been sighted in at least two sites. The very high intra-annual SFI values and the

259 significantly lower inter-annual SFI values suggest that movements rarely occur during winter,

260 but rather that birds may change wintering location between winters. These data also support the

261 idea that movements are probably not influenced by stress caused by our catching events.

262 Although we did not have the statistical power to analyse how the probability of movement

263 changes over the course of the winter, the majority of sanderlings seem to select a wintering site

264 early after arrival from their High Arctic breeding areas and remain faithful to that site over the

265 rest of the winter. The occupation of wintering sites in Ghana seems to be regulated by a buffer

266 effect, indicating that when sanderlings' wintering sites have reached their carrying capacity,

267 individuals were forced to use other non-preferred sites (Ntiamoa-Baidu et al. 2014). Hence, the

268 first arriving birds in autumn are more likely to return to previously used winter sites. Given that

269 juveniles arrive later in the wintering areas than adults (e.g. Lemke et al. 2012), the juveniles

270 would be more prone to be forced to non-preferred sites.

271 Both age and sex influenced the level of site fidelity of sanderlings. However, since we did

272 not sex juveniles, we cannot determine if there is any interaction between these two variables.

273 The lower site fidelity exhibited by juveniles seems to be in line with evidence from other avian

274 species where younger birds show larger home ranges (Warnock \& Takekawa 1996) and are

275 more likely to switch roosting and feeding locations (Rehfisch et al. 1996) during winter. In fact,

276 an experimental study involving displacement of dunlins Calidris alpina showed that site fidelity

277 of juveniles seems to increase even within their first winter. Birds that were moved later in the

278 winter were more likely to show "homing" behaviour (Baccetti et al. 1999). Although this age 
279 effect is not observed in all bird species (e.g. Diefenbach et al. 1988; Fox et al. 1994; Monsarrat

280 et al. 2013), such differences may reflect the fact that, as age increases, birds may be using

281 accumulated knowledge of site specific characteristics or past experiences to develop preferences

282 for particular sites, while dominance can also play a role with juveniles being more easily

283 displaced by older, more dominant individuals (e.g. Groves 1978). Consequently, older animals

284 with presumably greater knowledge of wintering site characteristics and more past experiences

285 may show increased fidelity to wintering sites which they found to be profitable and/or safe,

286 similarly to what is known for breeding site fidelity (e.g. Serrano et al. 2001).

287 Unlike previous studies, which did not find sexual differences in winter site fidelity of waders

288 (e.g. Warnock \& Takekawa 1996; Catry et al. 2012), we detected significantly lower site fidelity

289 in females within a single winter. It must be noted that this difference is quite small, with the vast

290 majority of birds of both sexes remaining faithful to their wintering site throughout the winter.

291 This small difference may have hampered its detection in previous studies using different

292 methods. In the breeding areas, many bird species show higher site fidelity in the sex that

293 establishes territories (Greenwood 1980; Gienapp \& Merilä 2011). Sanderlings can also be

294 territorial in winter (Myers et al. 1979) so we cannot rule out that territoriality may play a role

295 here, but since sanderlings are also gregarious and frequently change group composition within

296 the same foraging site (Myers 1983; Roberts \& Evans 1993) this seems unlikely. Lower site

297 fidelity could indicate that females have less benefits from prior knowledge of their foraging or

298 roosting sites, or more benefits from exploring alternative foraging sites if for instances their

299 preferred prey has a different distribution than that from the males (Alves et al. 2013). However,

300 since sanderlings shows little sexual dimorphism (Engelmoer \& Roselaar 1998; supplementary

301 information to this study), there is no evidence for differences in energetic costs or foraging 
302 behaviour that could drive the observed sexual difference. In fact, the few cases in which sexual

303 differences in winter site fidelity have been reported in bird species which make frequent

304 movements during winter following changes in food availability, or species in which pair bonds

305 or family group composition affect wintering distributions (e.g. Roberts \& Cook 1999; Wunderle

306 et al. 2014). Further studies will be required to confirm whether the sexual trend in winter site

307 fidelity we observed is a general feature in sanderlings, and potentially other site-faithful long-

308 distance migrants.

309 Overall, and despite the discussed sexual and age differences, sanderlings are highly site

310 faithful to their wintering sites. Also, the observed movements are mostly on a small scale and

311 there was only a single case of a bird moving between sites located further than $20 \mathrm{~km}$ apart. In

312 fact, Oeiras was never used by any marked bird and this site is located $20.5 \mathrm{~km}$ away from the

313 nearest estuarine site where birds were marked (Seixal), while Caparica which is just $14.5 \mathrm{~km}$

314 away from the same site was used by 6 marked individuals. This suggests that $15-20 \mathrm{~km}$ is

315 indeed the maximum distance sanderlings are likely to move among wintering sites under stable

316 conditions. As is the case for most studies focusing on animal dispersal (Nathan et al. 2003), our

317 study is also hampered by the impossibility to sample all potential areas past a limited distance.

318 The maximum distance between our study sites was $29.8 \mathrm{~km}$, which is a very considerable

319 distance and larger than in many similar studies (e.g. Evans et al. 1980; Groen 1993; Burton \&

320 Evans 1997; Leyrer et al. 2006), but we still may be failing to detect movements to areas located

321 further away. There is also the possibility that within this $30 \mathrm{~km}$ radius birds could use other sites

322 within and in the vicinity of the estuary that were not monitored, although the relatively rare

323 occurrence of sandy substrates in the Tejo estuary and the known preference sanderlings show

324 for these substrates suggest this is unlikely (Lourenço et al. 2015). Also, since ringing only took 
325 place in the three sites within the estuary, and not on the furthest sites located outside the estuary,

326 while the latter were probably visited less often, there might be a bias against detecting

327 movements over larger distances.

328 Still, even when considering these biases and limitations, there is a clear pattern of site fidelity

329 and decreasing chance of movements over increasing distances. The few birds ever detected

330 outside the estuary originated from the sites nearer the mouth of the estuary (mainly the nearest,

331 Seixal), and never from the site located the furthest (Alcochete) even though this was the site

332 with the largest number of individual birds ringed and sighted. The few sightings elsewhere

333 along the Portuguese coast of sanderlings that were colour-marked in other countries than

334 Portugal, suggest similar site fidelity: from 37 sightings of 12 individuals (average sightings per

335 individual: $3.1 \pm 2.0$ ), each observed in a single winter, only one was observed at two locations

336 which were separated by less than $4 \mathrm{~km}$ (Póvoa de Varzim $41^{\circ} 23^{\prime} \mathrm{N} / 8^{\circ} 46^{\prime} \mathrm{W}$ and Vila do Conde

$\left.33741^{\circ} 21^{\prime} \mathrm{N} / 8^{\circ} 45 \mathrm{~W}\right)$.

338 Altogether, our data suggest that sanderlings in and around the Tejo estuary rarely move

339 among wintering sites located at distances of more than $15 \mathrm{~km}$. Such a level of site fidelity

340 during winter is likely to confer advantages related to previous knowledge of foraging locations,

341 potential predation risks, and social interactions with other individuals using the same areas (e.g.

342 Alerstam 1990; Snell-Rood \& Cristol 2005), but may also limit the ability of these birds to detect

343 new areas of favourable habitat that may become available for colonization (Matthiopoulos et al.

3442005 ) or even of avoiding the consequences of any degradation to their traditional wintering sites

345 (e.g. Porzig et al. 2014).

346 In the Netherlands, individually recognisable sanderlings have been observed to move over

347 tens of kilometres in response to a sudden increase in food availability generated by a storm 
348 washing up large amounts of American Jack knife clam Ensis americanus on the shore (J.

349 Reneerkens unpubl. data), suggesting that sanderlings are able to react to the availability of new

350 foraging opportunities. Also, in the Solent estuary, UK, marked sanderlings seem to move

351 regularly among feeding sites located $15-20 \mathrm{~km}$ apart (P.M. Potts unpubl. data). There is no

352 evidence that any of the three areas we studied within the Tejo estuary suffered significant

353 changes during the course of this study, so we cannot predict whether the birds would move if

354 there was any decline in habitat quality, but these anecdotal observation from The Netherlands

355 and UK suggest that they are able to move to a larger extent than we observed in the Tejo.

356 However, at Caparica, the beaches are known to be suffering from severe coastal erosion and are

357 estimated to be retreating inland at an average rate of $7{\mathrm{~m} . y e a r^{-1}}^{1}$ as a result of river damming and

358 dredging, inadequate coastal management and urban pressure, and sea-level rise (Ferreira \&

359 Matias 2013). These beaches only persist there due to intense artificial sediment nourishment

360 (Ferreira \& Matias 2013) which can result in severe ecological impacts and loss of biodiversity

361 (Schlacher et al. 2007). In fact, data collected in parallel to this study indicate both food

362 availability and sanderling intake rates are currently lower in Caparica than in the sites within the

363 estuary (Lourenço et al. 2015). Despite this, sanderlings continue to use this site and the few

364 birds ringed in the estuary that were sighted in Caparica continued to use the site throughout the

365 winter. This may indicate that site fidelity is a stronger driver of habitat selection for sanderlings

366 than foraging habitat quality (as far as we can measure it) with potentially negative consequences

367 for birds using areas suffering fast human-mediated changes such as the case of many coastal

368 areas worldwide (Zhang et al. 2004; Schlacher et al. 2007). 
371

372

373

374

375

376

377

378

379

380

381

382

383

384

385

386

387

388

389

390

391

392

393

394

395

\section{Acknowledgements}

We would like to thank all the observers who voluntarily sent us sightings of our colourmarked birds, including several members of the Farlington Ringing Group who routinely visit the Tejo estuary and provided great help in catching, marking and re-sighting sanderlings. Particularly, Ruth Croger, Anne de Pottier and Mark Fletcher visited our study areas each winter and were an important help in the field. We would also like to thank Afonso Rocha, Sara Pardal and Miguel Braga for help in catching and marking sanderlings.

\section{References}

Alerstam, T. 1990. Bird migration. Cambridge University Press. Cambridge, UK.

Alves, J.A., Gunnarsson, T.G., Potts, P.M., Sutherland, W.J. \& Gill, J.A. 2013. Sex-biases in distribution and resource use at different spatial scales in a sexually dimorphic migratory shorebird. Ecology \& Evolution 3: 1079-1090.

Baccetti, N., Serra, L., Cherubini, G. \& Magnani, A. 1999. Timing of attachment to wintering site as revealed by experimental displaced dunlins (Calidris alpina). Journal of Ornithology 140: $309-317$.

Battin, J. 2004. When good animals love bad habitats: ecological traps and the conservation of animal populations. Conservation Biology 18: 1482-1491.

Burton, N.H.K. \& Evans, P.R. 1997. Survival and winter site-fidelity of turnstone Arenaria interpres and purple sandpiper Calidris maritima in northeast England. Bird Study 44: 35-44.

Catry, P., Catry I., Catry, T. \& Martins, T. 2003. Within and between-year winter site fidelity in chiffchaffs Phylloscopus collybita. Ardea 91: 213-220.

Catry, T., Alves, J.A., Gill, J.A., Gunnarsson, T.G. \& Granadeiro, J.P. 2012. Sex promotes 
396 spatial and dietary segregation in a migratory shorebird during the non-breeding season. PLoS

397 ONE 7: e33811. doi:10.1371/journal.pone.0033811.

398 Clarke, A.L., Sæther, B.-E- \& Røskaft, E. 1997. Sex biases in avian dispersal: a reappraisal. 399 Oikos 79: 429-438.

400 Clobert, J., Danchin, É., Dhondt, A.A. \& Nichols, J. Dispersal. Oxford University Press. Oxford, $401 \quad$ UK.

402 Conklin J.R., Reneerkens J., Verkuil Y.I., Tomkovich P., Palsbøll P.J. \& Piersma T. 2016. Low

403 genetic differentiation between Greenlandic and Siberian Sanderling populations implies a

404 different phylogeographic history than found in Red Knots. Journal of Ornithology 157: 325-

405332.

406 Connolly, L.M. \& Colwell, M.A. 2005. Comparative use of longline oysterbeds and adjacent 407 tidal flats by waterbirds. Bird Conservation International 15: 237-255.

408 Haas, C.A. 1998. Effects of prior nesting success on site fidelity and breeding dispersal: an 409 experimental approach. Auk 115: 929-936.

410 Delany, S., Scott, D., Dodman, T. \& Stroud, D. (eds.) 2009. An atlas of wader populations in 411 Africa and Western Eurasia. Wetlands International. Wageningen, The Netherlands.

412 Diefenbach, D.R., Nichols, J.D. \& Hines, J.E. 1988. Distribution patterns during winter and 413 fidelity to wintering areas of American black ducks. Canadian Journal of Zoology 66: 15064141513.

415 Donázar, J.A. \& Feijóo, J.E. 2002. Social structure of Andean condor roosts: influence of sex, 416 age and season. Condor 104: 832-837.

417 Evans, P.R., Breary, D.M. \& Goodyer, L.R. 1980. Studies on sanderling at Teesmouth, NE 418 England. Wader Study Group Bulletin 30: 18-20. 
419 Engelmoer, M. \& Roselaar, C.S. 1998. Geographic variation in waders. Kluwer Academic 420 Publishers. Dordrecht. The Netherlands.

421 Ferreira, Ó. \& Matias, A. 2013. Portugal. In: Pranzini, E. \& Williams, A. (eds.) Coastal erosion 422 and protection in Europe. Routledge, Oxfordshire. pp. 275-293.

423 Fox, A.D., Mitchell, C., Stewart, A., Fletcher, J.D., Turner, J.V.N., Boyd, H., Shimmings, P., 424 Salmon, D.G., Haines, W.G. \& Tomlinson, C. 1994. Winter movements and site fidelity of 425 pink-footed geese Anser brachyrhynchus ringed in Britain, with particular emphasis on those 426 marked in Lancashire. Bird Study 41: 221-234.

427 Galbraith, H., Jones, R., Park, R., Clough, J., Herrod-Julius, S., Harrington, B. \& Page, G. 2002. 428 Global climate change and sea level rise: potential losses of intertidal habitat for shorebirds. 429 Waterbirds 25: 173-183.

430 Gienapp, P. \& Merilä, J. 2011. Sex-specific fitness consequences of dispersal in Siberian jays. 431 Behavioral Ecology and Sociobiology 65: 131-140.

432 Greenwood, P.J. 1980. Mating systems, philopatry and dispersal in birds and mammals. Animal 433 Behavior 28: 1140-1162.

434 Greenwood, P.J. \& Harvey, P.H. 1982. The natal and breeding dispersal of birds. Annual Review 435 of Ecology and Systematics 13: 1-21.

436 Groen, N.M. 1993. Breeding site tenacity and natal philopatry in the black-tailed godwit Limosa 437 l. limosa. Ardea 81: 107-113.

438 Grond, K., Ntiamoa-Baidu, Y., Piersma, T. \& Reneerkens, J. 2015. Prey type and foraging 439 ecology of Sanderlings Calidris alba in different climate zones: are tropical areas more 440 favourable than temperate sites? PeerJ 3: e1125.

441 Groves, S. 1978. Age-related differences in ruddy turnstone foraging and aggressive behaviour. 
Auk 95: 95-103.

443 Gudmundsson, G.A. \& Lindström, Å. 1992. Spring migration of sanderling Calidri alba through 444 SW Iceland: wherefrom and whereto. Ardea 80: 315-326.

445 Gunnarsson, T.G., Sutherland, W.J., Alves, J.A., Potts, P.M. \& Gill, J.A. 2012. Rapid changes in 446 phenotype distribution during range expansion in a migratory bird. Proceedings of the Royal $447 \quad$ Society B 279: 411-416.

448 Harvey, P.H., Greenwood, P.J., Perrins, C.M. 1979. Breeding area fidelity of great tit (Parus 449 major). Journal of Animal Ecology 48: 305-313.

450 Hobson, K.A. 2005. Using stable-isotopes to trace long-distance dispersal in birds and other taxa. $451 \quad$ Diversity and Distributions 11: 157-164.

452 Jackson, D.B. 1994. Breeding dispersal and site-fidelity in three monogamous wader species in 453 the Western Isles, U.K. Ibis 136: 463-473.

454 Kirby, J.S. \& Lack, P.C. 1993. Spatial dynamics of wintering lapwings and golden plovers in 455 Britain and Ireland, 1981/82 to 1983/84. Bird Study 40: 38-50.

456 Kruckenberg, H. \& Borbach-Jaene, J. 2004. Do greylag geese (Anser anser) use traditional 457 roosts? Site fidelity of colour-marked Nordic greylag geese during spring migration. Journal 458 of Ornithology 145: 117-122.

459 Lemke, H.W., Bowler, J. \& Reneerkens J. 2012. Establishing the right period to estimate 460 juvenile proportions of wintering Sanderlings via telescope scans in western Scotland. Wader $461 \quad$ Study Group Bulletin 119: 129-132.

462 Leyrer, J., Spaans, B., Camara, M. \& Piersma, T. 2006. Small home ranges and high site fidelity 463 in red knots (Calidris c. canutus) wintering on the Banc d'Arguin, Mauritania. Journal of $464 \quad$ Ornithology 147: 376-384. 
465 Lourenço, P.M., Mandema, F.S., Hooijmeijer, J.C.E.W., Granadeiro, J.P. \& Piersma, T. 2010.

466 Site selection and resource depletion in black-tailed godwits Limosa l. limosa eating rice 467 during northward migration. Journal of Animal Ecology 79: 522-528.

468 Lourenço, P.M., Alves, J.A., Catry, T. \& Granadeiro, J.P. 2015. Foraging ecology of sanderlings

469 Calidris alba wintering in estuarine and non-estuarine intertidal areas. Journal of Sea $470 \quad$ Research 104: 33-40.

471 Loonstra, A.H.J., Piersma, T. \& Reneerkens, J. 2016. Staging duration and passage population 472 size of Sanderlings in the western Dutch Wadden Sea. Ardea 104: 49-61.

473 Matthiopoulos, J., Harwood, J. \& Thomas, L. 2005. Metapopulation consequences of site fidelity 474 for colonially breeding mammals and birds. Journal of Animal Ecology 74: 716-727.

475 Monsarrat, S., Benhamou, S., Sarrazin, F., Bessa-Gomes, C., Bouten, W. \& Duriez, O. 2013.

476 How predictability of feeding patches affects home range and foraging habitat selection in 477 avian social scavengers? PLOS ONE 8: e53077. doi:10.1371/journal.pone.0053077.

478 Myers, J.P. 1983. Space, time and the pattern of individual associations in a group-living species: 479 sanderlings have no friends. Behavioral Ecology and Sociobiology 12: 129-134.

480 Myers, J.P., Connors, P.J. \& Pitelka, F.A. 1979. Territory size in wintering sanderlings: the 481 effect of of prey abundance and intruder density. Auk 96: 551-561.

482 Myers, J.P., Sallaberry, M., Ortiz, A.E., Castro, G., Gordon, L.M., Maron, J.L., Schick, C.T., 483 Tabilo, E., Antas, P. \& Below, T. 1990. Migration routes of New World sanderlings. Auk 107: $484 \quad 172-180$.

485 Nathan, R., Perry, G., Cronin, J.T., Strand, A.E. \& Cain, M.L. 2003. Methods for estimating 486 long-distance dispersal. Oikos 103: 261-273.

487 Ntiamoa-Baidu, Y., Nuoh, A.A., Reneerkens, J. \& Piersma, T. 2014. Population increases in 
non-breeding Sanderlings in Ghana indicate site preference. Ardea 102: 131-137.

489 Oring, L.W. \& Lank, D. 1982. Sexual selection, arrival time, philopatry and site fidelity in the 490 polyandrous spotted sandpiper. Behavioral Ecology and Sociobiology 10: 185-191.

491 Pethick, J. 2001. Coastal management and sea-level rise. Catena 42: 307-322.

492 Porzig, E.L., Seavy, N.E., Gardali, T., Geupel, G.R., Holyoak, M. \& Eadie, J.M. 2014. Habitat 493 suitability through time: using time series and habitat models to understand changes in bird 494 density. Ecosphere 5: art12. http://dx.doi.org/10.1890/ES13-00166.1.

Refisch, M.M., Clark, N.A., Langston, R.H.W. \& Greenwood, J.J.D. 1996. A guide to the 496 provision of refuges for waders: an analysis of 30 years of ringing data from the Wash, England. Journal of Applied Ecology 33: 673-687.

Reneerkens, J., Benhoussa, A., Boland, H., Collier, M., Grond, K., Günther, K., Hallgrimsson, 499 G.T., Hansen, J., Meissner, W., de Meulenaer, B., Ntiamoa-Baidu, Y., Piersma, T., Poot, M., van Roomen, M., Summers, R.W., Tomkovich, P.S. \& Underhill, L.G. 2009. Sanderlings using African-Eurasian flyways: a review of current knowledge. Wader Study Group Bulletin 116: $2-20$.

503

Roberts, G. \& Evans, P.R. 1993. A method for the detection of non-random associations among 504 flocking birds and its application to sanderlings Calidris alba wintering in N.E. England. Behavioural Ecology and Sociobiology 32: 349-354.

Roberts, G.J. \& Cook, F. 1999. Winter philopatry in migratory waterfowl. Auk 116: : 20-34.

507 Schlacher, T.A., Dugan, J., Schoeman, D.S., Lastra, M., Jones, A., Scapini, F., McLachlan, A. \& 508 Defeo, O. 2007. Sandy beaches at the brink. Diversity and Distributions 13: 556-560.

509 Serrano, D., Tella, J.L., Forero, M.G. \& Donázar, J.A. 2001. Factors affecting breeding dispersal 510 in the facultatively colonial lesser kestrel: individual experience vs. conspecific cues. Journal 
of Animal Ecology 70: 568-578.

512 Snell-Rood, E.C. \& Cristol, D.A. 2005. Prior residence influences contest outcomes in flocks of

513 non-breeding birds. Ethology 111: 441-454.

514 Taft, O.W., Sanzenbacher, P.M. \& Haig, S.M. 2008. Movements of wintering dunlin Calidris

$515 \quad$ alpina and changing habitat availability in an agricultural wetland landscape. Ibis 150:

$516 \quad 541-549$.

517 Takekawa, J.Y., Warnock, N., Martinelli, G.M., Miles, A.K. \& Tsao, D.C. 2002. Waterbird use

518 of bayland wetlands in the San Francisco Bay estuary: movements of long-billed

519 dowitchers during the winter. Waterbirds 25(Sp2): 93-105.

520 van de Kam, J., Ens, B., Piersma, T. \& Zwarts, L. 2004. Shorebirds. An illustrated behavioural

521 ecology. KNNV Publishers. Utrecht, The Netherlands.

522

van Gils, J.A., Piersma, T., Dekinga, A., Spaans, B. \& Kraan, C. 2006. Shellfish dresging pushes

a flexible avian top predator out of a marine protected area. PLoS Biology 12: e376.

524

Vergara, P., Aguirre, J.I., Fargallo, J.A. \& Dávila, J.A. 2006. Nest-site fidelity and breeding success in White Stork Ciconia ciconia. Ibis 148: 672-677.

526

Warnock, S.E. \& Takekawa, J.Y. 1996. Wintering site fidelity and movement patterns of Western Sandpipers Calidris mauri in the San Francisco Bay estuary. Ibis 138: 160-167.

Wilson, H.J., Norriss D.W., Walsh A., Fox A.D. \& Stroud D.A. 1991. Winter site fidelity in 529 Greenland white-fronted geese Anser albifrons flavirostris, implications for conservation and management. Ardea 79: 287-294.

531 Wunderle, J.M., Lebow, P.K., White, J.D., Currie, D. \& Ewert, D.N. Sex and age differences in 532 site fidelity, food resource tracking, and body condition of wintering Kirtland's warblers 533 (Setophaga kirtlandii) in the Bahamas. Ornithological Monographs 80: 1-62. 
534 Yosef, R. \& Meissner, W. 2006. Seasonal age differences in weight and biometrics of migratory 535 dunlins (Calidris alpina) at Eilat, Israel. Ostrich 77: 67-72.

536 Zhang, K., Douglas, B.C. \& Leatherman, S.P. 2004. Global warming and coastal erosion.

$537 \quad$ Climatic Change 64: 41-58.

538 
539 Table 1: Details on the data collected for the 160 marked sanderlings used in this study,

540 including the number of individuals that were marked and sighted each winter (cumulative

541 number in parenthesis), the number of sightings per individual each winter (average \pm SE, range

542 in parenthesis) and the average number of visits per site each winter. Number of visits refers only

543 to visits when at least one marked bird was sighted as there is no way of estimating the number

544 of visits made by volunteers when no sightings were reported. Since marked birds were only

545 detected in Caparica in 2012/13, the average only includes this site for that winter.

\begin{tabular}{lcccc}
\hline & $\mathbf{2 0 0 9} / \mathbf{1 0}$ & $\mathbf{2 0 1 0} / \mathbf{1 1}$ & $\mathbf{2 0 1 1} / \mathbf{1 2}$ & $\mathbf{2 0 1 2} / \mathbf{1 3}$ \\
\hline Marked individuals & $44(44)$ & $28(72)$ & $42(114)$ & $46(160)$ \\
Sighted individuals & 29 & 33 & 71 & 124 \\
Sightings per individual & $4.0 \pm 0.2$ & $3.9 \pm 0.2$ & $4.4 \pm 0.2$ & $5.6 \pm 0.23$ \\
& $(3-7)$ & $(3-8)$ & $(3-14)$ & $(3-17)$ \\
Visits per site & $5.7 \pm 1.2$ & $7.0 \pm 1.5$ & $15.7 \pm 1.6$ & $19.3 \pm 4.0$ \\
& $(3$ sites $)$ & $(3$ sites $)$ & $(3$ sites $)$ & $(4$ sites $)$ \\
\hline
\end{tabular}


550 Figure 1: Map of the study area and proportion of birds sighted in each site that were either only

551 sighted locally or also sighted in other sites. Panel A refers to the average per winter (4 winters

552 for all sites except Caparica for each we only had sightings of colour-marked birds in 2012-13).

553 Panel B refer to all winters combined. Each site is represented by a different colour (Alcochete:

554 red, Samouco: yellow, Seixal: green, Caparica: blue, Oeiras: pink) and in the pie charts the

555 proportion of birds only sighted locally have the colour of that site and the proportions of birds

556 also sighted elsewhere have the colours of the other sites in which they were sighted. Number of

557 marked individuals (n) that were detected at each site during the time span of the study:

$558 \mathrm{n}_{\text {Alcochete }}=88, \mathrm{n}_{\text {Samouco }}=42, \mathrm{n}_{\text {Seixal }}=39$ and $\mathrm{n}_{\text {Caparica }}=6$.

561 Figure 2: Effect of distance between sites on the probability of movements occurring among

562 them. The grey symbols and GLMM regression line refer to a single winter (average of all four 563 winters), while the black symbols and line refer to multiple winters. Each dot shows the average

564 probability of movement for a given distance. For each pair of sites, the number of marked

565 individuals ranged from 40 (Seixal-Caparica) to 117 (Alcochete-Samouco).

566

567 Figure 3: Comparison of Site Fidelity Index (SFI) values between sexes (A and B) and age 568 classes (C and D), and between a single winter and multiple winters (E). Panel A represents 569 average intra-annual SFI values for males $(n=64)$ and females $(n=38)$; panel B represents average

570 inter-annual SFI values for males $(n=42)$ and females $(n=31)$; panel C presents average intra571 annual SFI values for adults $(n=126)$ and juveniles $(n=34)$ in the winter when they were 572 ringed/aged; panel D presents average intra-annual SFI values of 24 birds ringed as juveniles 
573 when considering their first winter (juveniles) and a subsequent winter (adults); and panel E

574 presents average intra and inter-annual SFI values of 101 birds ringed as adults. The black dots 575 represent the mean, the boxes represent standard errors and the whiskers represent the range. * $576 \mathrm{p}<0.05, * * \mathrm{p}<0.01, * * * \mathrm{p}<0.001$ 
578 Fig. 1
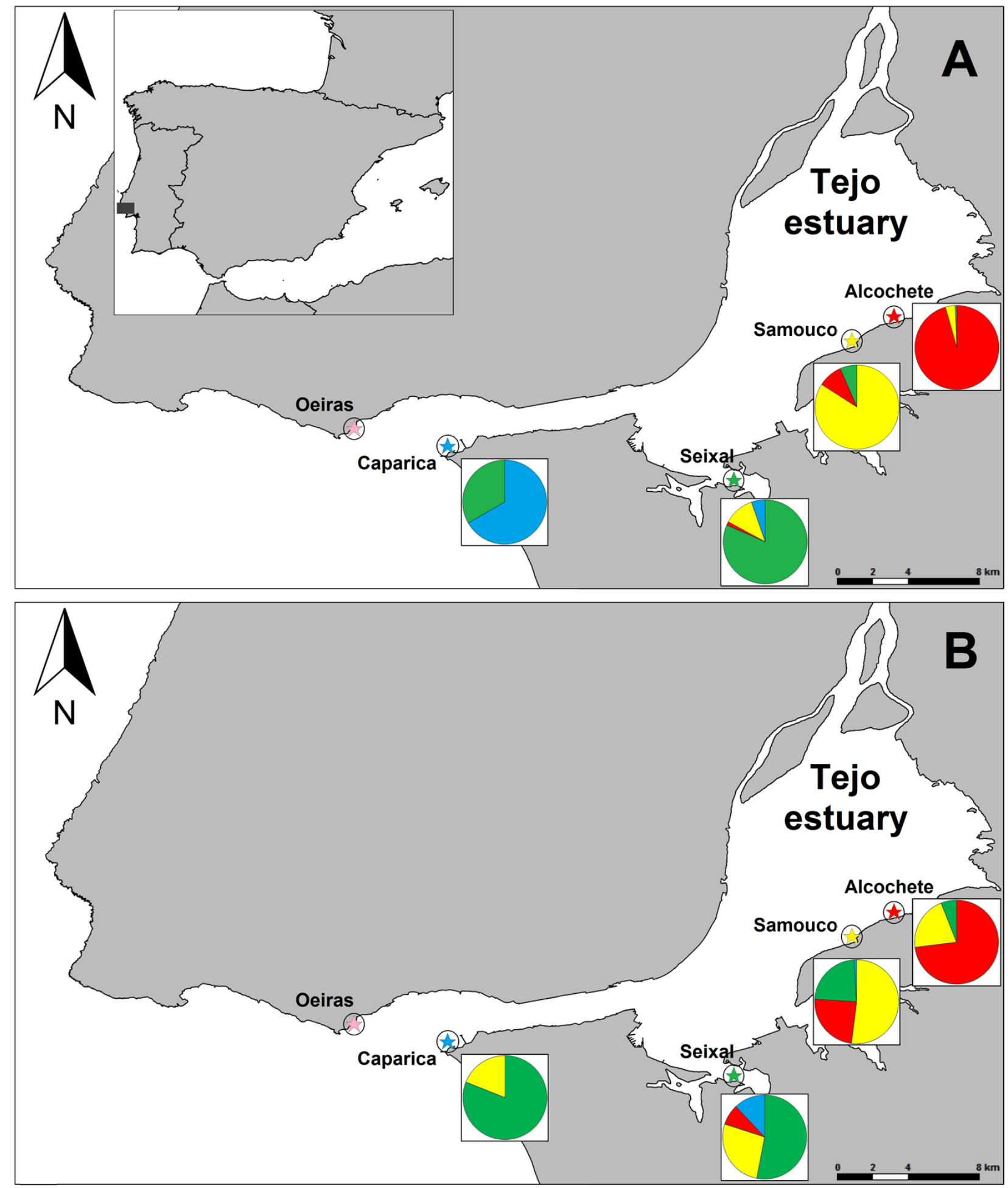
582 Fig. 2

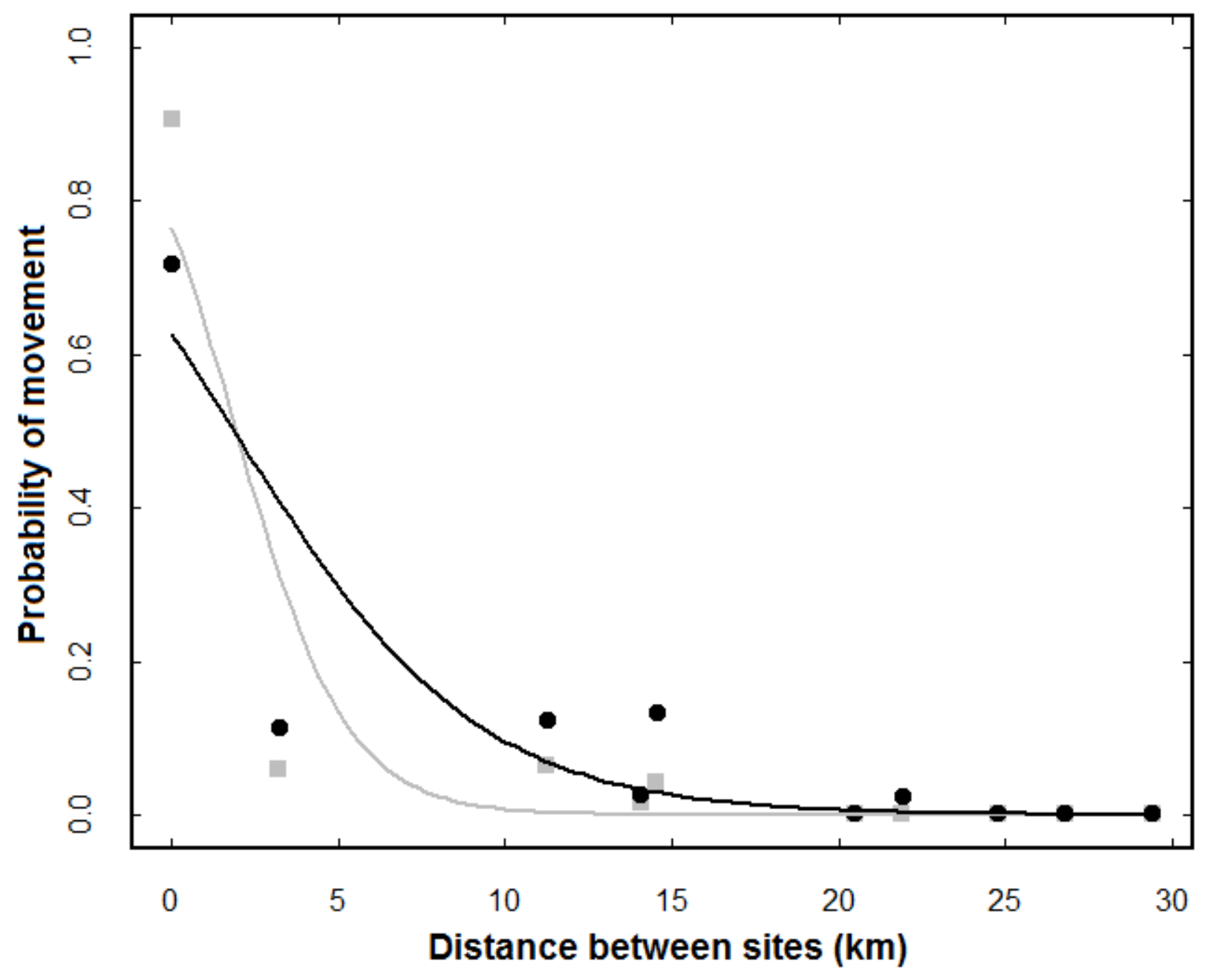

583

584

585 
586 Fig. 3

A: Intra-annual

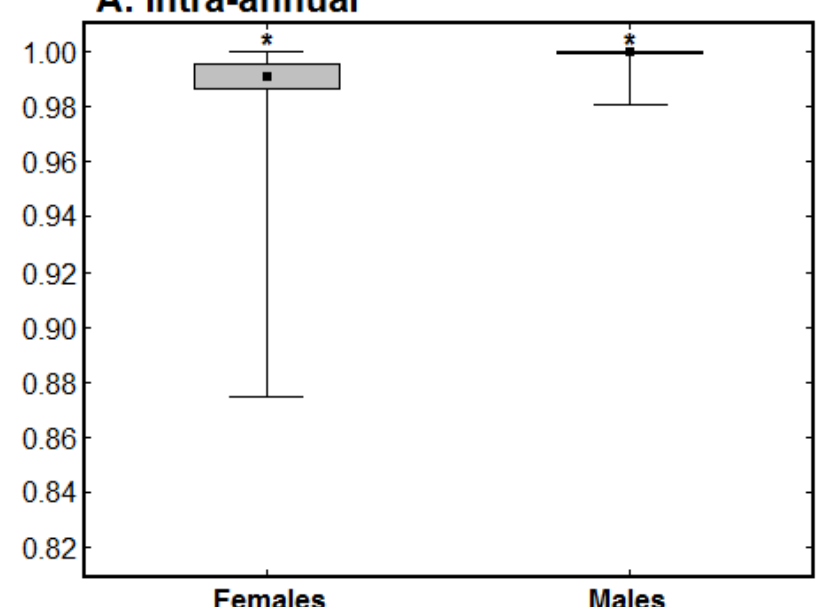

C: Intra-annual

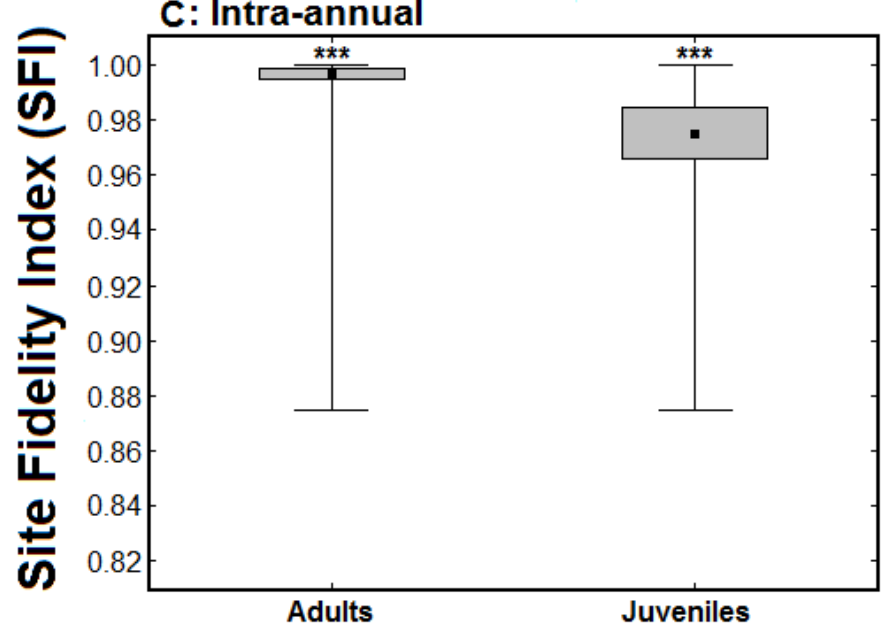

E: Adults

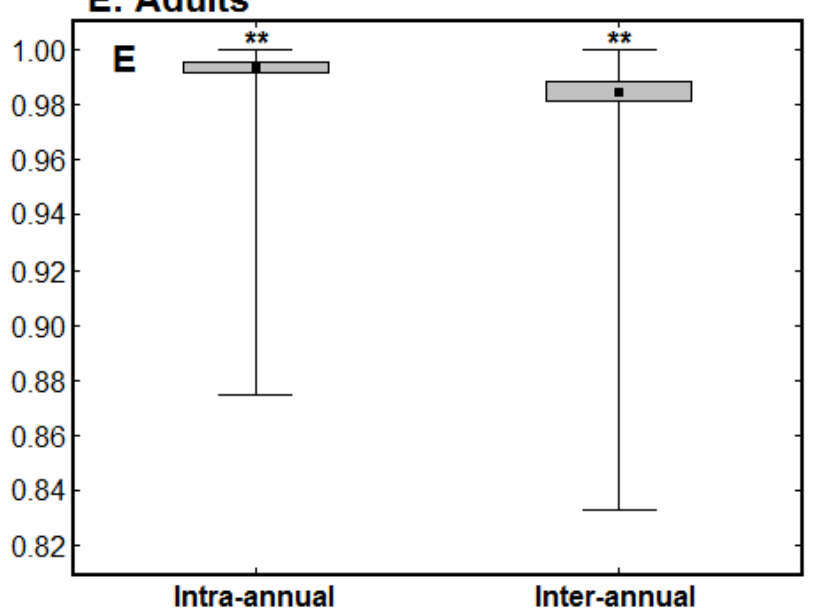

B: Inter-annual

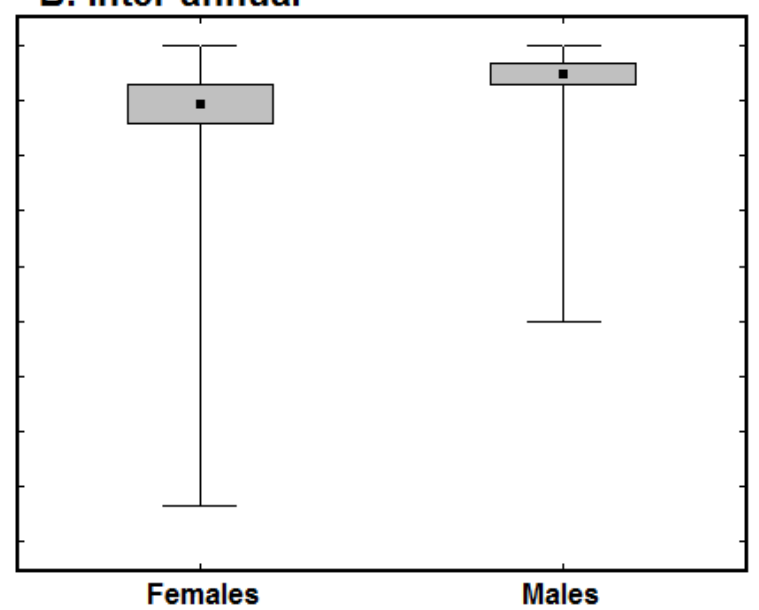

D: Inter-annual

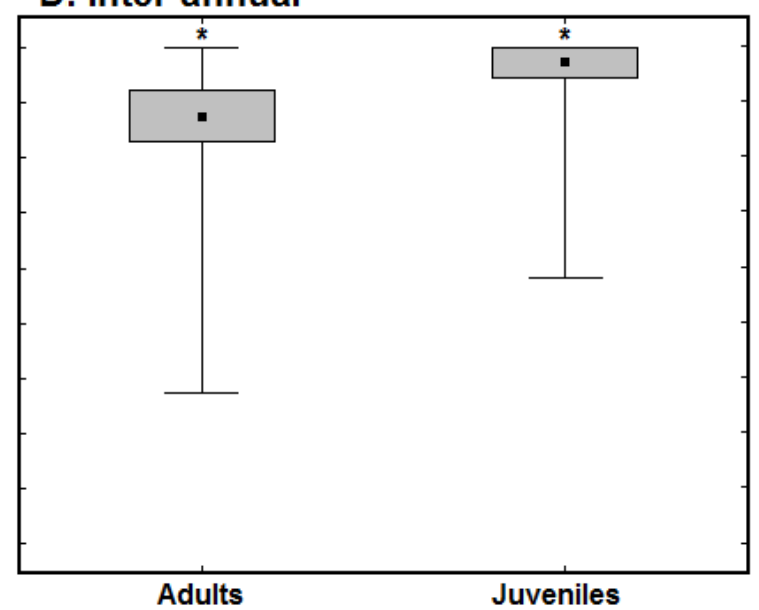

587 